\title{
Current Research in Necrotizing Enterocolitis
}

\author{
Simon Eaton ${ }^{1}$, Clare M. Rees ${ }^{1}$ and Nigel J Hall ${ }^{2}$ \\ ${ }^{1}$ UCL Institute of Child Health and Great Ormond Street Hospital for Children, \\ London, UK, ${ }^{2}$ Faculty of Medicine, University of Southampton, Southampton, UK
}

Corresponding author:

\author{
Simon Eaton, PhD \\ Department of Paediatric Surgery, \\ UCL Institute of Child Health, \\ 30 Guilford Street, \\ London, \\ WC1N 1EH \\ UK
}

Telephone: +44 (0)207905 2158

Fax: $+44(0) 2074046181$

Email: s.eaton@ucl.ac.uk 
Keywords: necrotizing enterocolitis, intestinal microbiota, premature infants, inflammation, TLR4, surgery 


\section{Abstract}

Despite decades of research on necrotizing enterocolitis, we still do not fully understand the pathogenesis of the disease, how to prevent or how to treat the disease. However, as a result of recent significant advances in the microbiology, molecular biology, and cell biology of the intestine of premature infants and infants with necrotizing enterocolitis, there is some hope that research into this devastating disease will yield some important translation into improved outcomes.

\section{Introduction}

Although necrotizing enterocolitis (NEC) is one of the most common life-threatening surgical diseases affecting neonates, we still do not completely understand the pathogenesis or how to prevent or treat the disease [1]. The high mortality (around 30\% for surgical NEC [2, 3] and longterm morbidity [4] [5] of survivors mandates urgent research into the pathogenesis, diagnosis, prevention and treatment of this devastating disease. There are several animal models of NEC, however, it is not completely clear how accurately these models recapitulate the human disease. This is particularly difficult as clinical NEC itself is quite variable, with some authors arguing for sub-classification into different forms reflecting the differences in disease onset and progression between a 'typical' NEC presentation in an extremely premature infant who has been fed enterally for a few weeks, and other presentations such as NEC in a term infant who has a cardiac defect or who has had gastroschisis [6]. As a consequence of the limitations of the animal models, it is vital to undertake clinical research studies in parallel with basic science / animal model studies, and in this brief review article, our aim is to describe some areas of current research interest; an exhaustive review of all current NEC research is unfeasible. 


\section{Pathogenesis}

The main factors thought to be involved in the pathogenesis of NEC are: intestinal immaturity, enteral feeds, the intestinal microbiome, inflammation and local ischaemia and/or reperfusion injury. We will briefly discuss recent research in each of these areas below.

\section{Intestinal immaturity}

The fetal gut develops in an environment where exposure to microbes is limited. Therefore, premature infants are exposed to a much greater diversity and quantity of bacteria, viruses and fungi. The premature infant gut displays an excessive inflammatory response [7], and toll-like receptor 4 seems to play a key role in this inflammatory response ([8] see below). However, a difference in inflammatory response is not the only aspect of the premature infant intestine that might be affected. The neonatal gut also seems to be more susceptible to intestinal ischaemia/reperfusion injury than adult gut [9], and the activity of carbohydrate digestive enzymes is significantly lower in preterm intestine than term intestine, so that in a pig model the incidence and severity of NEC can be modulated by variation in the carbohydrate supplied [10]. Although gut motility appears is to be different in preterm and term infants [11], NEC does not seem to be related to early stooling pattern in premature infants [12]. Another potentially important difference between premature and term infants is that of maternal separation. Partial separation of mouse pups from the mother is enough to induce changes in colonic histology and permeability [13], although the relevance of these observations to NEC is unknown.

\section{Enteral feeding}

Although it has long been known that firstly, NEC predominantly occurs in premature infants that have been enterally fed, and secondly that human breast milk is protective towards NEC, we do not completely understand how the type of feed interacts with other risk factors. Interestingly, the protective effect of breast milk appears to be dose related [14]. A huge array 
of protective factors present in breast milk has been suggested (summarized [15]) and some of these have been suggested as potential preventative measures or treatments (see below). One mechanism by which feed components could influence intestinal gene expression is epigenetics, with epigenetic changes defined as 'relating to or arising from non-genetic influences on gene expression'. As epigenetic changes frequently involve methylation, they are potentially influenced by diet. A current area of research interest is the potential epigenetic effects of breast milk and other enteral feeds [16]. Marked epigenetic changes have been observed in the intestine of premature infants [17], and in a pig model, enteral feeding has been linked with epigenetic changes causing upregulation of pro-inflammatory genes [18]. In addition, the type of enteral feed can also interact with other risk factors described below such as the gut microbiome [19] and intestinal blood flow [20].

\section{Intestinal microbiome}

While the precise role of bacterial agents in the development of NEC is unclear, several factors implicate their involvement. Occasionally NEC is observed to occur in clusters, in which a higher than expected number of cases are observed in one centre [21]. Identical organisms are grown from babies within these clusters and the initiation of infection control measures has been shown to control such outbreaks [22]. However, different organisms are grown from separate outbreaks so it cannot be claimed that a single organism is involved in development of NEC. Bacterial involvement in the pathogenesis of NEC is also implicated by association; endotoxaemia $[23,24]$ and positive blood cultures are common in infants with NEC and the gastrointestinal pneumatosis found in NEC contains $30 \%$ hydrogen [25], a gas produced solely by bacterial metabolism. As long ago as 1975 , it was hypothesized that a dysbiosis (imbalance between protective microflora and harmful microflora) was involved in the pathogenesis of NEC [26]. The recent explosion of interest in the intestinal microbiome, and the availability of high 
throughput pyrosequencing techniques, has led to several relevant research studies in NEC. However, such data are very complex, and analysis of these data in a very heterogeneous disease like NEC is extremely challenging, especially where both the nosocomial microbiota and their measurement methods vary between neonatal units [27]. Nevertheless, recent studies suggested a loss in microbial diversity to occur immediately before NEC onset $[28,29]$, with a consequent predominance of Escherichia spp. [28] or strict anaerobes [29].

\section{Inflammation}

Histologically, there is a massive intestinal inflammatory response in NEC. Some authors have even suggested that there may be antenatal precedents to this exaggerated inflammatory response, such as chorioamnionitis. A recent systematic review and meta-analysis of available studies concluded that chorioamnionitis with fetal involvement, and clinical chorioamnionitis both significantly increased the risk of NEC, whereas there was no increased risk from histological chorioamnionitis [30]. Differences in the immune response to mucosal damage and the microbiota may also be responsible for the exaggerated inflammatory response in NEC (reviewed [31]). Recent studies have highlighted such differences, such as those showing that intraepithelial T cell receptor $\gamma \delta$ lymphocytes are decreased in surgical NEC specimens compared with appropriate controls [32] as are lamina propria T regulatory cells [33]. A key player in intestinal inflammation and the response to pathogens is TLR4, and recent work has shown that TLR4 signalling is important in the development of NEC [8, 34-36]. Intriguingly, TLR4 signalling also links to other factors involved in the pathogenesis of NEC, such as the microcirculation ([36] see below).

Ischaemic injury

From early descriptions, ischaemia/reperfusion injury due to relative splanchnic hypoperfusion (the so called 'diving reflex') was though to play a part in the pathogenesis of NEC 
[26], in part due to the similarity in histological damage between intestinal ischaemic damage (such as that following mesenteric infarction) and NEC. A primary role for intestinal ischaemic damage long fell out of favour (for discussion, see [37]), but recently some evidence from both animal models and clinical studies has resurrected the potential role of intestinal ischaemia, although probably not as the sole initiating factor. Experimental studies have suggested that in NEC, there is an impairment in intestinal microcirculation [37-39] which can be improved by direct peritoneal resuscitation [40-43]. A potential role for splanchnic hypoperfusion in NEC has been suggested from a variety of clinical studies: firstly, there is a decline in mesenteric oxygenation when preterm infants are fed during red blood cell transfusion [44] (which may itself be associated with precipitation of acute NEC [45]). Secondly, there is increasing recognition that an important subset of infants with NEC have congenital cardiac disease that may predispose to splanchnic hypoperfusion [46]. Thirdly, several clinical studies have suggested that arginine and/or citrulline, amino acids which are important in production of nitric oxide and regulation of intestinal blood flow, are decreased in NEC and that supplementation of infants with arginine may prevent NEC [47-51]. Interestingly, the importance of the arginine/citrulline axis in pathogenesis of NEC is also emphasized by other studies which show that regulation of the genes of arginine biosynthesis is altered in human NEC $[52,53]$, that amount of proteins of the arginine biosynthetic pathway is altered in experimental NEC [54], that polymorphisms in the enzyme carbamoyl phosphate synthase, a key gene in arginine biosynthesis, are associated with NEC development [55] and that experimental enterocyte-specific knockdown of the enzyme argininosuccinate lyase results in an increased incidence of NEC [56]. However, it should also be noted the function of arginine is not solely related to regulation of blood flow, but that it is also an important amino acid in immune function and wound healing, two other processes that are potentially impaired in NEC. 


\section{Diagnosis}

Diagnosis of NEC currently relies on a combination of clinical symptoms and signs, and radiological features such as pneumatosis intestinalis and pneumoperitoneum, which are encapsulated in the Bell's stages of disease, which although frequently criticized, are still widely used to describe populations of infants with NEC. For many years, researchers have sought biomarkers that would be diagnostic for NEC in plasma, urine or stool samples (reviewed [57, 58]). One of the most widely researched proposed biomarkers is intestinal fatty acid binding protein (I-FABP), which is released into the circulation from damaged enterocytes, and is excreted in urine. It has been shown in many studies that I-FABP is increased around the time of development of NEC $[59,60]$. However, I-FABP concentrations in healthy premature infants are somewhat variable and the half-life of I-FABP in plasma is short, so that use of I-FABP concentration in plasma or urine to diagnose early NEC is limited. Similarly, although I-FABP can usefully distinguish those infants that have more extensive disease and thus require more extensive resection $[59,61]$, the short half-life means that unless there is ongoing enterocyte damage, some infants with very extensive disease can have paradoxically low I-FABP levels (presumably as all the enterocytes have been lost) [59]. Recently, biomarker discovery studies of the urinary proteome [62] and peptidome [63] have identified proteins and peptides associated with poor outcome (i.e. disease progression). Importantly, the biomarkers alone were not able to completely distinguish progressors from non-progressors, but were able to when clinical factors were incorporated into the prediction model too. This raises the question of the clinical utility of these markers - neither an ELISA (for I-FABP) nor mass-spectrometry are currently anywhere near point-of-care testing, so whether they can be usefully incorporated into medical and surgical decision making, particularly when clinical information also has to be taken into account, is uncertain. 
Another type of biomarker that has also seen recent interest is the use of analysis of volatile organic compounds (VOCs) in stool samples as markers of bacterial metabolism. In one pilot study, it was shown that a difference in VOC profile in stool samples between control infants and infants with NEC could be used to predict NEC before clinical symptoms [64], and a larger study aimed to corroborate these findings is currently underway. Another recent study used an 'electronic nose' system, in which VOCs are not quantitatively measured, but differences in intensity across an array of sensors are used to discriminate samples. The study showed that fecal VOC profiles of infants with NEC could be discriminated from controls, from 2-3 days predating the onset of clinical symptoms [65]. Again, there may be problems in utilizing these interesting biomarkers in a clinically useful way,

Given that most very low birthweight or extremely low birthweight infants will have some form of continual monitoring of heart rate, pulse oximetry and other physiological parameters, it would be useful to incorporate these measures into early warning tools to predict NEC. Some neonatal units are now incorporating sophisticated analysis algorithms into their bedside monitoring, and ultimately these may provide just such a prediction tool. Abnormal heart rate characteristics have been suggested as a useful clinical tool to predict clinical neonatal sepsis [66], and have shown initial promise to predict NEC before clinical diagnosis in a prospective trial setting [67]. However, a more recent study in which the same system was used in routine clinical practice suggested that abnormal heart rate characteristics have limited ability to detect sepsis [68].

The role of ultrasound as an imaging modality for infants with NEC has attracted research interest $[69,70]$. Whilst plain radiology remains the primary imaging modality for diagnostic purposes it is clear that ultrasound has promise for imaging infants with NEC. Pneumatosis intestinalis and portal venous gas are both readily seen during abdominal 
ultrasound and in fact PVG may be detected earlier by US than by plain radiography [71]. However it is the ability of ultrasound to detect infants with more advanced disease and those who may benefit from surgery that has attracted greatest attention. Ultrasound permits examination of the intestinal wall in a much more detailed way than is possible with plain radiographs and in particular allows an assessment of the thickness and perfusion of the intestinal wall and peristalsis $[72,73]$. Characteristic perfusion patterns have been associated with inflammation, ischaemia and necrosis [72]. Further information that can be obtained from ultrasound also includes the presence of free intra-abdominal gas and the presence and nature of any free intra-abdominal fluid that may be indicative of intestinal perforation. The real challenge is to determine whether US can be used to accurately identify infants with NEC who would benefit from surgery [72][74]). Further prospective evaluation is undoubtedly needed.

Near infra-red spectroscopy (NIRS) has also been investigated by researchers who believe it may be useful at predicting risk of NEC [75][76], distinguishing infants with NEC from those without and for the identification of infants with advanced NEC. NIRS measures oxygenation at the tissue level using probes placed on the skin and is limited by a short depth of tissue penetration, typically $(<1 \mathrm{~cm})$. NIRS probes placed on the abdominal wall may therefore give an indication of the state oxygenation of some of the underlying intestine. NIRS does not have the ability however to determine oxygenation in the entire intestine. Despite this, differences have been detected in splanchnic tissue oxygenation values using NIRS between preterm infants who subsequently developed NEC and those who did not $[75,76][77]$. Whether NIRS can be used with clinical benefit to prevent NEC with infants with NEC remains to be seen.

\section{Prevention}

Dietary / pharmacological approaches 
There are several suggested dietary and/or pharmacological approaches to the prevention of NEC. Many of these agents are found in human breast milk, for example lactoferrin is a glycoprotein that forms part of the innate immune response. It is found in high concentration in colostrum and lower concentration in breast milk and has antibacterial and antiviral properties. It has been speculated that it would be a potential preventative measure for NEC, but few animal or human studies have yet been carried out to establish its efficacy. A small randomised study in VLBW infants found that episodes of sepsis were reduced in infants given oral human lactoferrin (4.4 vs. $17.3 / 1,000$ patient days, $p=0.007$ ) but none in the treatment or placebo group developed NEC [78]. A randomised controlled trial of bovine lactoferrin showed a reduced incidence of NEC compared to controls, and a reduced risk of death or progression to stage 3 NEC [79]. Oligosaccharides are complex carbohydrates that are components present at much higher concentration in human breast milk than formula. They have been shown to prevent NEC in a rodent model [80], have shown promise in preventing NEC in a limited human trial [81] and seem to have generated a recent flurry of activity amongst patent lawyers. Another series of compounds that have potential use in preventing NEC is a new class of TLR4 inhibitors, which by preventing TLR4 activation may inhibit the inflammatory cascade in NEC $[82,83]$.

\section{Probiotics}

A huge amount of interest and hope bordering on evangelism has been invested in the routine administration of probiotics to prevent or eradicate this disease. Neonatologists are quite polarized on the issue of probiotics to prevent NEC: proponents of probiotics regard the fact that probiotics are not routinely given to premature neonates as unethical, detractors regard the meta-analyses combining different probiotic strains as deeply scientifically flawed. The American Pediatric Surgical Association Outcomes and Clinical Trials Committee considered the level of evidence for routine probiotic supplementation and concluded that 'Substantial data 
support routine supplementation of enteral intake with probiotics in premature infants to reduce the incidence of severe NEC (Grade $A / B$ ). No formal recommendations regarding the formulation, timing or duration of supplementation could be determined, but at least one probiotic formulation initiated in the first week of life and continued for at least two weeks appears appropriate.' [84]. However, it was also noted in this review that 'No conclusions regarding probiotic use in ELBW (<1000 grams) infants could be extrapolated from the studies due to limited data.'. As this population of preterm infants is exactly that at the most risk from NEC, we need further evidence of efficacy and safety in this group, and eagerly await the results of the UK based PIPs trial, which recruited 1315 infants <31 weeks completed gestation [85]. One aspect that contributes to unease regarding clinical uptake of probiotics, but might ultimately help to define a product, is the lack of mechanistic understanding of how probiotics might prevent NEC. The literature on potential mechanisms of probiotic action is mainly from experimental models. Although there are various experimental models of NEC, and several have been used to examine the effects of probiotics in NEC, none seem to completely recapitulate the human condition [86]. Data from a clinically relevant model (spontaneous NEC in premature pigs) hint as to why routine introduction of probiotics is less than straightforward. In 2 separate studies, by the same group, divergent results were obtained [87, 88]. In one study, probiotics decreased severity of NEC lesions (but did not affect incidence) [87], whereas in the other, probiotics significantly increased the incidence and severity of NEC [88]. These differing results illustrate in a microcosm the multifactorial and unpredictable nature of NEC and why we might not always expect consistent effects from probiotic administration to premature infants with very different microbiota.

A general assumption is that probiotics may reduce the incidence of NEC by altering the gut microbiome in favour of a more 'friendly' population of bacterial species which in turn reduces 
the risk of NEC. However, alteration of gut flora is only one potential mechanism by which probiotics might prevent NEC. Other mechanisms include effects on the gut immune system and via TLR-related signaling $[89,90]$ and effects on mucosal integrity and intestinal permeability $[91,92]$. However, whether these are primary or secondary effects is extremely difficult to dissect, as the microbiome, immune system, mucosal integrity and gut barrier function are all mutually interdependent. Mechanistic studies in human infants are clearly difficult, but the group of Walker and Nanthakumar [93] has established protocols using immature human intestine that provides mechanistic insights. In one of these, intestinal tissue from therapeutic terminations of pregnancy is implanted in immune-deficient mice, the xenografts allowed to mature for 20 or 30 weeks to model immature intestine (i.e. susceptible to NEC) or mature intestine respectively, and then challenged with inflammatory stimuli. In addition, enterocytes were isolated from resected ileum of an infant with NEC. Using these model systems, probiotic bacteria decreased inflammation, but, intriguingly, these effects could be reproduced by a small soluble factor produced by the probiotic bacteria. These data are supported by further studies which suggest that soluble factors secreted by Bifidobacterium infantis and Lactobacillus acidophilus are effective in preventing enterocyte damage $[94,95]$. If this soluble factor(s) were to be identified, it might be possible to use this factor pharmacologically for NEC prophylaxis, which may be easier to get accepted into routine clinical practice than a pot pourri of probiotics. Intriguingly, it has recently been suggested that the bacterial DNA alone of the probiotic strain Lactobacillus rhamnosus HNOO1 is sufficient to protect against NEC in a mouse model via activation of the TLR9 pathway [96]. A greater mechanistic understanding of the actions of probiotics may also allow development of surrogate endpoints of effectiveness, and refinement of probiotic regimes, as well as development of pharmacological agents. 


\section{Therapy}

Antibiotics are the mainstay of conservative treatment of NEC. The type of agent used varies between neonatal units, with little evidence to support one regime over another. A Cochrane review in 2014 found only two small trials, dating from the 1980s which compared different regimes including ampicillin, gentamicin and clindamycin [97]. An association between clindamycin and increased risk of post-NEC stricture was found and clindamycin is not recommended. Recently a cohort study found that adding metronidazole to broad spectrum antibiotics did not prevent deterioration of established NEC [98]. A large Canadian case control study of anaerobic antimicrobials found decreased mortality in surgical patients, but an increased risk of strictures in infants who had anaerobic antibiotics including Clindamycin, Metronidazole, Piperacillin-Tazobactam and Carbapenems. They observed a decrease in the use of Clindamycin and an increasing use of Metronidazole over a 15 year period [99]. They recommend a trial to assess the safety of different antibiotic regimes in neonatal care (SCAMP NCT01994993)[100].

Debates on the risks of enteral feeding in causing or worsening NEC continue, but a study recently tried to establish whether parenteral nutrition was protective - limited by its nature as a retrospective cohort study, it found that infants on PN were more likely to have NEC earlier in life, but had no increase in the need for surgery or mortality [101]. It would be interesting to study this effect in a randomised controlled trial.

Research into medical treatments for NEC have focused on agents that modulate the immune response, as an immature immune response is thought to be a factor in the pathogenesis of NEC [102]. A Cochrane review found that there was very weak evidence for the use of pentoxifylline, a phosphodiesterase inhibitor, as an adjunct to antibiotics in the treatment of sepsis in neonates, with a relative risk of NEC of $0.62[0.26,1.43][103,104]$ In a rat model, intra- 
peritoneal pentoxifylline reduced the incidence and severity of NEC [105], but trials comparing the use of IV pentoxifylline in premature neonates have not yet been completed.[106]

Another potential medical treatment is intestinal alkaline phosphatase (IAP), a protein found in the intestinal brush border and secreted in the bowel lumen. Previous studies have shown that exogenous IAP may prevent intestinal damage, but unfortunately a recent study using a rat model of NEC did not find that it was an effective treatment once NEC was initiated [107].

Recent evidence from three different research groups has suggested that stem cells are able to influence the course of the disease in experimental NEC (reviewed [108]): amniotic fluid stem cells [109], mesenchymal stem cells $[110,111]$ and enteric neural stem system cells [112]. In addition to the beneficial effects of AFS cells and the conditioned medium from AFS cells, other recent evidence highlights the potential role of factors in amniotic fluid in the prevention and/or treatment of NEC. Pig and human amniotic fluid, centrifuged so presumed to be largely cell-free, have been shown to stimulate proliferation and migration of rat intestinal epithelial cells in vitro [113]. In a well-established, clinically relevant model of spontaneous NEC in preterm piglets, postnatal minimal enteral feeding with porcine amniotic fluid decreased inflammation together with incidence and severity of NEC[114], but had no effect when given later, with full enteral feeding, although the beneficial effect during minimal enteral feeding was not consistently observed [113] [114]. Another group has shown that enteral delivery of amniotic fluid decreases severity of NEC in a mouse model [115]. This effect was shown to be mediated via epidermal growth factor (EGF) present in amniotic fluid, and its receptor, epidermal growth factor rector (EGFR). In additional experiments, both in vitro and in vivo it was shown that amniotic fluid modulates the ability of lipopolysaccharide to trigger toll-like 4- receptor (TLR4) -dependent inflammatory signalling, and these effects were mediated via EGF/EGFR[115]. It has also been 
suggested that these protective effects of amniotic fluid are mediated via hepatocyte growth factor [116].

\section{Conclusions}

Despite understanding the cardinal features involved in the pathogenesis of NEC, and decades of research, we still do not fully understand this devastating disease, how to prevent it or treat it. Nevertheless, the broad range and depth of research on the topic does lead to a degree of optimism that clinicians and scientists will hopefully be able to deliver novel preventative, diagnostic and therapeutic strategies that will translate into improved outcomes.

\section{Research Directions}

- Testing of research-based biomarkers in large clinical cohorts to determine whether they improve decision-making

- Improve understanding of the interplay between microbiota and intestinal inflammation

- Elucidation of the molecular basis of the protective effect of probiotics, in order to optimise probiotic strains to be used in prevention of NEC

\section{Acknowledgements}

SE gratefully acknowledges support from Great Ormond Street Hospital Children's Charity and NJH is supported by the NIHR Southampton Biomedical Research Centre in Nutrition.

\section{Conflict of interest statement:}

Simon Eaton has received consultancy fees from Fresenius Kabi and a speaker's honorarium from Danone. The authors have no other relevant financial interests or affiliations.

\section{References}


[1] Hall NJ, Eaton S, Pierro A. Necrotizing enterocolitis: Prevention, treatment, and outcome. Journal of Pediatric Surgery. 2013;48:2359-67.

[2] Fitzgibbons SC, Ching Y, Yu D, Carpenter J, Kenny M, Weldon C, et al. Mortality of necrotizing enterocolitis expressed by birth weight categories. J Pediatr Surg. 2009;44:1072-5.

[3] Thyoka M, De Coppi P, Eaton S, Khoo K, Hall NJ, Curry J, et al. Advanced necrotizing enterocolitis part 1: mortality. EurJ PediatrSurg. 2012;22:8-12.

[4] Kelleher J, Mallick H, Soltau TD, Harmon CM, Dimmitt RA. Mortality and intestinal failure in surgical necrotizing enterocolitis. J Pediatr Surg. 2013;48:568-72.

[5] Rees CM, Pierro A, Eaton S. Neurodevelopmental outcomes of neonates with medically and surgically treated necrotizing enterocolitis. ArchDisChild Fetal Neonatal Ed. 2007;92:F193-F8.

[6] Gordon PV, Swanson JR. Necrotizing enterocolitis is one disease with many origins and potential means of prevention. Pathophysiology. 2014;21:13-9.

[7] Nanthakumar NN, Fusunyan RD, Sanderson I, Walker WA. Inflammation in the developing human intestine: A possible pathophysiologic contribution to necrotizing enterocolitis. ProcNatlAcadSciUS A. 2000;97:6043-8.

[8] Hackam DJ, Good M, Sodhi CP. Mechanisms of gut barrier failure in the pathogenesis of necrotizing enterocolitis: Toll-like receptors throw the switch. Seminars in Pediatric Surgery. 2013;22:76-82.

[9] Yu Y, Klemann C, Feng X, Ginzel M, Vieten G, Lacher M, et al. Increased inflammatory reaction to intestinal ischemia-reperfusion in neonatal versus adult mice. Eur J Pediatr Surg. $2015 ; 25: 46-50$.

[10] Thymann T, Moller HK, Stoll B, Stoy AC, Buddington RK, Bering SB, et al. Carbohydrate maldigestion induces necrotizing enterocolitis in preterm pigs. Am J Physiol GastrointestLiver Physiol. 2009;297:G1115-G25. 
[11] Bekkali N, Hamers SL, Schipperus MR, Reitsma JB, Valerio PG, Van Toledo L, et al. Duration of meconium passage in preterm and term infants. Archives of Disease in Childhood - Fetal and Neonatal Edition. 2008;93:F376-F9.

[12] Gregory KE, Winston AB, Meller S, Ismail A, Van Marter LJ. Stooling Pattern and Early Nutritional Exposures Associated With Necrotizing Enterocolitis in Premature Infants. Journal of Perinatal \& Neonatal Nursing. 2015;29:60-8.

[13] Li B, Lee C, Zani A, Zani-Ruttenstock E, Ip W, Chi L, et al. Early maternal separation induces alterations of colonic epithelial permeability and morphology. Pediatr Surg Int. 2014;30:121722.

[14] Meinzen-Derr J, Poindexter B, Wrage L, Morrow AL, Stoll B, Donovan EF, et al. Role of human milk in extremely low birth weight infants' risk of necrotizing enterocolitis or death. Journal of Perinatology. 2009;29:57-62.

[15] Caplan MS. Neonatal necrotizing enterocolitis: Clinical observations, pathophysiology, and prevention. In: Martin RJ, Fanarof AA, editors. Fanaroff and Martin's Neonatal-Perinatal Medicine: Diseases of the Fetus and Infant. 9th ed. Missouri: Mosby; 2010. p. 1431-40.

[16] Verduci E, Banderali G, Barberi S, Radaelli G, Lops A, Betti F, et al. Epigenetic effects of human breast milk. Nutrients. 2014;6:1711-24.

[17] Gao F, Zhang J, Jiang P, Gong D, Wang JW, Xia Y, et al. Marked methylation changes in intestinal genes during the perinatal period of preterm neonates. BMC Genomics. 2014;15:716.

[18] Willems R, Krych L, Rybicki V, Jiang P, Sangild PT, Shen RL, et al. Introducing enteral feeding induces intestinal subclinical inflammation and respective chromatin changes in preterm pigs. Epigenomics. 2015;7:553-65.

[19] Trinchese G, Cavaliere G, Canani RB, Matamoros S, Bergamo P, De Filippo C, et al. Human, donkey and cow milk differently affects energy efficiency and inflammatory state by modulating 
mitochondrial function and gut microbiota. The Journal of Nutritional Biochemistry. 2015;26:1136-46.

[20] Schroeder VA, Mattioli LF, Kilkenny TA, Belmont JM. Effects of lactose-containing vs lactosefree infant formula on postprandial superior mesenteric artery flow in term infants. JPEN J Parenter Enteral Nutr. 2014;38:236-42.

[21] van Acker J, de Smet F, Muyldermans G, Bougatef A, Naessens A, Lauwers S. Outbreak of necrotizing enterocolitis associated with Enterobacter sakazakii in powdered milk formula. J ClinMicrobiol. 2001;39:293-7.

[22] Rotbart HA, Levin MJ. How contagious is necrotizing enterocolitis? PediatrlnfectDis. $1983 ; 2: 406-13$.

[23] Scheifele DW. Role of bacterial toxins in neonatal necrotizing enterocolitis. Journal of Pediatrics. 1990;117:S44-S6.

[24] Scheifele DW, Olsen EM, Pendray MR. Endotoxinemia and thrombocytopenia during neonatal necrotizing enterocolitis. AmJClinPathol. 1985;83:227-9.

[25] Cheu HW, Brown DR, Rowe MI. Breath hydrogen excretion as a screening test for the early diagnosis of necrotizing enterocolitis. Am J DisChild. 1989;143:156-9.

[26] Santulli TV, Schullinger JN, Heird WC, Gongaware RD, Wigger J, Barlow B, et al. Acute necrotizing enterocolitis in infancy: a review of 64 cases. Pediatrics. 1975;55:376-87.

[27] Niemarkt HJ, de Meij TG, van de Velde ME, van der Schee MP, van Goudoever JB, Kramer BW, et al. Necrotizing enterocolitis: a clinical review on diagnostic biomarkers and the role of the intestinal microbiota. Inflamm Bowel Dis. 2015;21:436-44.

[28] Stewart CJ, Marrs EC, Nelson A, Lanyon C, Perry JD, Embleton ND, et al. Development of the preterm gut microbiome in twins at risk of necrotising enterocolitis and sepsis. PLoS One. 2013;8:e73465. 
[29] Brower-Sinning R, Zhong D, Good M, Firek B, Baker R, Sodhi CP, et al. Mucosa-Associated Bacterial Diversity in Necrotizing Enterocolitis. PLoS ONE. 2014;9:e105046.

[30] Been JV, Lievense S, Zimmermann LJ, Kramer BW, Wolfs TG. Chorioamnionitis as a risk factor for necrotizing enterocolitis: a systematic review and meta-analysis. J Pediatr. 2013;162:236-42 e2.

[31] McElroy SJ, Weitkamp JH. Innate Immunity in the Small Intestine of the Preterm Infant. Neoreviews. 2011;12:e517-e26.

[32] Weitkamp JH, Rosen MJ, Zhao Z, Koyama T, Geem D, Denning TL, et al. Small intestinal intraepithelial TCRgammadelta+ T lymphocytes are present in the premature intestine but selectively reduced in surgical necrotizing enterocolitis. PLoS One. 2014;9:e99042.

[33] Weitkamp JH, Koyama T, Rock MT, Correa H, Goettel JA, Matta P, et al. Necrotising enterocolitis is characterised by disrupted immune regulation and diminished mucosal regulatory (FOXP3)/effector (CD4, CD8) T cell ratios. Gut. 2013;62:73-82.

[34] Good M, Sodhi CP, Egan CE, Afrazi A, Jia H, Yamaguchi Y, et al. Breast milk protects against the development of necrotizing enterocolitis through inhibition of Toll-like receptor 4 in the intestinal epithelium via activation of the epidermal growth factor receptor. Mucosal Immunol. 2015;8:1166-79.

[35] Afrazi A, Branca MF, Sodhi CP, Good M, Yamaguchi Y, Egan CE, et al. Toll-like receptor 4mediated endoplasmic reticulum stress in intestinal crypts induces necrotizing enterocolitis. J Biol Chem. 2014;289:9584-99.

[36] Yazji I, Sodhi CP, Lee EK, Good M, Egan CE, Afrazi A, et al. Endothelial TLR4 activation impairs intestinal microcirculatory perfusion in necrotizing enterocolitis via eNOS-NO-nitrite signaling. Proc Natl Acad Sci U S A. 2013;110:9451-6. 
[37] Watkins DJ, Besner GE. The role of the intestinal microcirculation in necrotizing enterocolitis. Seminars in Pediatric Surgery. 2013;22:83-7.

[38] Downard CD, Grant SN, Matheson PJ, Guillaume AW, Debski R, Fallat ME, et al. Altered intestinal microcirculation is the critical event in the development of necrotizing enterocolitis. Journal of Pediatric Surgery. 2011;46:1023-8.

[39] Ito Y, Doelle SM, Clark JA, Halpern MD, McCuskey RS, Dvorak B. Intestinal microcirculatory dysfunction during the development of experimental necrotizing enterocolitis. Pediatric Research. 2007;61:180-4.

[40] Downard CD, Matheson PJ, Shepherd JA, Maki AC, Garrison RN. Direct peritoneal resuscitation augments ileal blood flow in necrotizing enterocolitis via a novel mechanism. Journal of Pediatric Surgery. 2012;47:1128-34.

[41] Maki AC, Matheson PJ, Shepherd JA, Garrison RN, Downard CD. Intestinal Microcirculatory Flow Alterations in Necrotizing Enterocolitis are Improved by Direct Peritoneal Resuscitation. American Surgeon. 2012;78:803-7.

[42] Walker SK, Matheson PJ, Galganski LA, Garrison RN, Downard CD. Application of prostaglandin E-2 improves ileal blood flow in NEC. Journal of Pediatric Surgery. 2014;49:945-9.

[43] Walker SK, Matheson PJ, Schreiner MT, Smith JW, Garrison RN, Downard CD. Intraperitoneal 1.5\% Delflex improves intestinal blood flow in necrotizing enterocolitis. Journal of Surgical Research. 2013;184:358-64.

[44] Marin T, Josephson CD, Kosmetatos N, Higgins M, Moore JE. Feeding Preterm Infants during Red Blood Cell Transfusion Is Associated with a Decline in Postprandial Mesenteric Oxygenation. Journal of Pediatrics. 2014;165:464-+. 
[45] Christensen RD, Lambert DK, Henry E, Wiedmeier SE, Snow GL, Baer VL, et al. Is "transfusion-associated necrotizing enterocolitis" an authentic pathogenic entity? Transfusion. 2010;50:1106-12.

[46] Motta C, Scott W, Mahony L, Koch J, Wyckoff M, Reisch J, et al. The association of congenital heart disease with necrotizing enterocolitis in preterm infants: a birth cohort study. J Perinatol. 2015;35:949-53.

[47] Amin HJ, Zamora SA, McMillan DD, Fick GH, Butzner JD, Parsons HG, et al. Arginine supplementation prevents necrotizing enterocolitis in the premature infant. JPediatr. 2002;140:425-31.

[48] Becker RM, Wu GY, Galanko JA, Chen WN, Maynor AR, Bose CL, et al. Reduced serum amino acid concentrations in infants with necrotizing enterocolitis. Journal of Pediatrics. 2000;137:78593.

[49] Celik IH, Demirel G, Canpolat FE, Dilmen U. Reduced Plasma Citrulline Levels in Low Birth Weight Infants With Necrotizing Enterocolitis. Journal of Clinical Laboratory Analysis. 2013;27:328-32.

[50] Zamora SA, Amin HJ, McMillan DD, Kubes P, Fick GH, Butzner JD, et al. Plasma L-arginine concentrations in premature infants with necrotizing enterocolitis. Journal of Pediatrics. 1997;131:226-32.

[51] Polycarpou E, Zachaki S, Tsolia M, Papaevangelou V, Polycarpou N, Briana DD, et al. Enteral L-arginine supplementation for prevention of necrotizing enterocolitis in very low birth weight neonates: a double-blind randomized pilot study of efficacy and safety. JPEN J Parenter Enteral Nutr. 2013;37:617-22. 
[52] Chan KYY, Leung KT, Tam YH, Lam HS, Cheung HM, Ma TPY, et al. Genome-wide Expression Profiles of Necrotizing Enterocolitis Versus Spontaneous Intestinal Perforation in Human Intestinal Tissues Dysregulation of Functional Pathways. Annals of Surgery. 2014;260:1128-37.

[53] Ng PC, Chan KYY, Leung KT, Tam YH, Ma TPY, Lam HS, et al. Comparative MiRNA Expressional Profiles and Molecular Networks in Human Small Bowel Tissues of Necrotizing Enterocolitis and Spontaneous Intestinal Perforation. Plos One. 2015;10.

[54] Jiang P, Sangild PT. Intestinal proteomics in pig models of necrotising enterocolitis, short bowel syndrome and intrauterine growth restriction. Proteomics Clinical Applications. 2014;8:700-14.

[55] Moonen RM, Paulussen AD, Souren NY, Kessels AG, Rubio-Gozalbo ME, Villamor E. Carbamoyl Phosphate Synthetase Polymorphisms as a Risk Factor for Necrotizing Enterocolitis. Pediatric Research. 2007;62:188-90.

[56] Premkumar MH, Sule G, Nagamani SC, Chakkalakal S, Nordin A, Jain M, et al. Argininosuccinate lyase in enterocytes protects from development of necrotizing enterocolitis. American Journal of Physiology-Gastrointestinal and Liver Physiology. 2014;307:G347-G54.

[57] Ng PC, Ma TPY, Lam HS. The use of laboratory biomarkers for surveillance, diagnosis and prediction of clinical outcomes in neonatal sepsis and necrotising enterocolitis Archives of Disease in Childhood - Fetal and Neonatal Edition. 2015;100:F448-F52.

[58] Evennett NJ, Alexander N, Petrov M, Pierro A, Eaton S. A systematic review of serologic tests in the diagnosis of necrotizing enterocolitis. J Pediatr Surg. 2009;44:2192-201.

[59] Evennett N, Hall N, Pierro A, Eaton S. Urinary intestinal fatty acid-binding protein concentration predicts extent of disease in necrotizing enterocolitis. Journal of Pediatric Surgery. 2010;45:735-40. 
[60] Derikx JP, Evennett NJ, Degraeuwe PL, Mulder TL, van Bijnen AA, van Heurn LW, et al. Urine based detection of intestinal mucosal cell damage in neonates with suspected necrotising enterocolitis. Gut. 2007;56:1473-5.

[61] Heida FH, Hulscher JB, Schurink M, Timmer A, Kooi EM, Bos AF, et al. Intestinal fatty acidbinding protein levels in Necrotizing Enterocolitis correlate with extent of necrotic bowel: results from a multicenter study. J Pediatr Surg. 2015;50:1115-8.

[62] Sylvester KG, Ling XB, Liu GY, Kastenberg ZJ, Ji J, Hu Z, et al. Urine protein biomarkers for the diagnosis and prognosis of necrotizing enterocolitis in infants. J Pediatr. 2014;164:607-12 e1-7.

[63] Sylvester KG, Ling XB, Liu GY, Kastenberg ZJ, Ji J, Hu Z, et al. A novel urine peptide biomarker-based algorithm for the prognosis of necrotising enterocolitis in human infants. Gut. 2013.

[64] Garner CE, Ewer AK, Elasouad K, Power F, Greenwood R, Ratcliffe NM, et al. Analysis of faecal volatile organic compounds in preterm infants who develop necrotising enterocolitis: a pilot study. J Pediatr Gastroenterol Nutr. 2009;49:559-65.

[65] de Meij TGJ, van der Schee MPC, Berkhout DJC, van de Velde ME, Jansen AE, Kramer BW, et al. Early Detection of Necrotizing Enterocolitis by Fecal Volatile Organic Compounds Analysis. The Journal of Pediatrics.

[66] Sullivan BA, Fairchild KD. Predictive monitoring for sepsis and necrotizing enterocolitis to prevent shock. Semin Fetal Neonatal Med. 2015;20:255-61.

[67] Stone ML, Tatum PM, Weitkamp JH, Mukherjee AB, Attridge J, McGahren ED, et al. Abnormal heart rate characteristics before clinical diagnosis of necrotizing enterocolitis. J Perinatol. 2013;33:847-50. 
[68] Coggins SA, Weitkamp J-H, Grunwald L, Stark AR, Reese J, Walsh W, et al. Heart rate characteristic index monitoring for bloodstream infection in an NICU: a 3-year experience. Archives of Disease in Childhood - Fetal and Neonatal Edition. 2015.

[69] Bohnhorst B. Usefulness of abdominal ultrasound in diagnosing necrotising enterocolitis. Arch Dis Child Fetal Neonatal Ed. 2013;98:F445-50.

[70] Epelman M, Daneman A, Navarro OM, Morag I, Moore AM, Kim JH, et al. Necrotizing enterocolitis: Review of state-of-the-art imaging findings with pathologic correlation. Radiographics. 2007;27:285-305.

[71] Dordelmann M, Rau GA, Bartels D, Linke M, Derichs N, Behrens C, et al. Evaluation of portal venous gas detected by ultrasound examination for diagnosis of necrotising enterocolitis. Archives of Disease in Childhood-Fetal and Neonatal Edition. 2009;94:F183-F7.

[72] Faingold R, Daneman A, Tomlinson G, Babyn PS, Manson DE, Mohanta A, et al. Necrotizing enterocolitis: assessment of bowel viability with color doppler US. Radiology. 2005;235:587-94.

[73] Silva CT, Daneman A, Navarro OM, Moore AM, Moineddin R, Gerstle JT, et al. Correlation of sonographic findings and outcome in necrotizing enterocolitis. Pediatr Radiol. 2007;37:274-82.

[74] Yikilmaz A, Hall NJ, Daneman A, Gerstle JT, Navarro OM, Moineddin R, et al. Prospective evaluation of the impact of sonography on the management and surgical intervention of neonates with necrotizing enterocolitis. Pediatr Surg Int. 2014;30:1231-40.

[75] DeWitt AG, Charpie JR, Donohue JE, Yu S, Owens GE. Splanchnic near-infrared spectroscopy and risk of necrotizing enterocolitis after neonatal heart surgery. Pediatr Cardiol. 2014;35:128694.

[76] Patel AK, Lazar DA, Burrin DG, Smith EO, Magliaro TJ, Stark AR, et al. Abdominal nearinfrared spectroscopy measurements are lower in preterm infants at risk for necrotizing enterocolitis. Pediatr Crit Care Med. 2014;15:735-41. 
[77] Cortez J, Gupta M, Amaram A, Pizzino J, Sawhney M, Sood BG. Noninvasive evaluation of splanchnic tissue oxygenation using near-infrared spectroscopy in preterm neonates. J Matern Fetal Neonatal Med. 2011;24:574-82.

[78] Akin IM, Atasay B, Dogu F, Okulu E, Arsan S, Karatas HD, et al. Oral lactoferrin to prevent nosocomial sepsis and necrotizing enterocolitis of premature neonates and effect on Tregulatory cells. American journal of perinatology. 2014;31:1111-20.

[79] Manzoni P, Meyer M, Stolfi I, Rinaldi M, Cattani S, Pugni L, et al. Bovine lactoferrin supplementation for prevention of necrotizing enterocolitis in very-low-birth-weight neonates: a randomized clinical trial. Early human development. 2014;90 Suppl 1:S60-5.

[80] Jantscher-Krenn E, Zherebtsov M, Nissan C, Goth K, Guner YS, Naidu N, et al. The human milk oligosaccharide disialyllacto-N-tetraose prevents necrotising enterocolitis in neonatal rats. Gut. 2012;61:1417-25.

[81] Armanian A-M, Sadeghnia A, Hoseinzadeh M, Mirlohi M, Feizi A, Salehimehr N, et al. The Effect of Neutral Oligosaccharides on Reducing the Incidence of Necrotizing Enterocolitis in Preterm infants: A Randomized Clinical Trial. International journal of preventive medicine. 2014;5:1387-95.

[82] Wipf P, Eyer BR, Yamaguchi Y, Zhang F, Neal MD, Sodhi CP, et al. Synthesis of -inflammatory alpha-and beta-linked acetamidopyranosides as inhibitors of toll-like receptor 4 (TLR4). Tetrahedron Lett. 2015;56:3097-100.

[83] Neal MD, Jia H, Eyer B, Good M, Guerriero CJ, Sodhi CP, et al. Discovery and validation of a new class of small molecule Toll-like receptor 4 (TLR4) inhibitors. PLoS One. 2013;8:e65779.

[84] Downard CD, Renaud E, St Peter SD, Abdullah F, Islam S, Saito JM, et al. Treatment of necrotizing enterocolitis: an American Pediatric Surgical Association Outcomes and Clinical Trials Committee systematic review. Journal of Pediatric Surgery. 2012;47:2111-22. 
[85] Abernathy CO, Utili R, Zimmerman HJ. Immaturity of the biliary excretory system predisposes neonates to intrahepatic cholestasis. Med Hypotheses. 1979;5:641-7.

[86] Lu P, Sodhi CP, Jia H, Shaffiey S, Good M, Branca MF, et al. Animal models of gastrointestinal and liver diseases. Animal models of necrotizing enterocolitis: pathophysiology, translational relevance, and challenges. American Journal of Physiology - Gastrointestinal and Liver Physiology. 2014;306:G917-G28.

[87] Siggers RH, Siggers J, Boye M, Thymann T, Molbak L, Leser T, et al. Early administration of Probiotics alters bacterial colonization and limits diet-induced gut dysfunction and severity of necrotizing enterocolitis in preterm pigs. Journal of Nutrition. 2008;138:1437-44.

[88] Cilieborg MS, Thymann T, Siggers R, Boye M, Bering SB, Jensen BB, et al. The Incidence of Necrotizing Enterocolitis Is Increased Following Probiotic Administration to Preterm Pigs. Journal of Nutrition. 2011;141:223-30.

[89] Liu YY, Fatheree NY, Mangalat N, Rhoads JM. Lactobacillus reuteri strains reduce incidence and severity of experimental necrotizing enterocolitis via modulation of TLR4 and NF-kappa B signaling in the intestine. American Journal of Physiology-Gastrointestinal and Liver Physiology. 2012;302:G608-G17.

[90] Ganguli K, Collado MC, Rautava J, Lu L, Satokari R, von Ossowski I, et al. Lactobacillus rhamnosus GG and its SpaC pilus adhesin modulate inflammatory responsiveness and TLRrelated gene expression in the fetal human gut. Pediatric Research. 2015;77:528-35.

[91] Patel RM, Myers LS, Kurundkar AR, Maheshwari A, Nusrat A, Lin PW. Probiotic Bacteria Induce Maturation of Intestinal Claudin 3 Expression and Barrier Function. American journal of pathology. 2012;180:626-35.

[92] Khailova L, Patrick SKM, Arganbright KM, Halpern MD, Kinouchi T, Dvorak B. Bifidobacterium bifidum reduces apoptosis in the intestinal epithelium in necrotizing 
enterocolitis. American Journal of Physiology-Gastrointestinal and Liver Physiology. 2010;299:G1118-G27.

[93] Ganguli K, Meng D, Rautava S, Lu L, Walker WA, Nanthakumar N. Probiotics prevent necrotizing enterocolitis by modulating enterocyte genes that regulate innate immunemediated inflammation. American Journal of Physiology-Gastrointestinal and Liver Physiology. 2013;304:G132-G41.

[94] Shiou S-R, Yu Y, Guo Y, He S-M, Mziray-Andrew CH, Hoenig J, et al. Synergistic Protection of Combined Probiotic Conditioned Media against Neonatal Necrotizing Enterocolitis-Like Intestinal Injury. PLoS ONE. 2013;8:e65108.

[95] Guo S, Guo Y, Ergun A, Lu L, Walker WA, Ganguli K. Secreted Metabolites of $<$ italic $>$ Bifidobacterium infantis</italic $>$ and $<$ italic $>$ Lactobacillus acidophilus $</$ italic $>$ Protect Immature Human Enterocytes from IL-1ß-Induced Inflammation: A Transcription Profiling Analysis. PLoS ONE. 2015;10:e0124549.

[96] Good M, Sodhi CP, Ozolek JA, Buck RH, Goehring KC, Thomas DL, et al. Lactobacillus rhamnosus HNOO1 decreases the severity of necrotizing enterocolitis in neonatal mice and preterm piglets: evidence in mice for a role of TLR92014.

[97] Shah D, Sinn JK. Antibiotic regimens for the empirical treatment of newborn infants with necrotising enterocolitis. The Cochrane database of systematic reviews. 2012;8:CD007448.

[98] Luo LJ, Li X, Yang KD, Lu JY, Li LQ. Broad-spectrum Antibiotic Plus Metronidazole May Not Prevent the Deterioration of Necrotizing Enterocolitis From Stage II to III in Full-term and Nearterm Infants: A Propensity Score-matched Cohort Study. Medicine. 2015;94:e1862.

[99] Autmizguine J, Hornik CP, Benjamin DK, Jr., Laughon MM, Clark RH, Cotten CM, et al. Anaerobic antimicrobial therapy after necrotizing enterocolitis in VLBW infants. Pediatrics. 2015;135:e117-25. 
[100] Cohen-Wolkowiez M. Antibiotic Safety (SCAMP) - Full Text View - ClinicalTrials.gov. 2015.

[101] Akinkuotu ACN, Sushma; Sheikh, Fariha; Cruz, Stephanie M.; Welty, Stephen E., Olutoye, Oluyinka O. The effect of supplemental parenteral nutrition on outcomes of necrotizing enterocolitis in premature, low birth weight neonates. 2015.

[102] Lin PW, Nasr TR, Stoll BJ. Necrotizing enterocolitis: recent scientific advances in pathophysiology and prevention. Seminars in perinatology. 2008;32:70-82.

[103] Pammi M, Haque KN. Pentoxifylline for treatment of sepsis and necrotizing enterocolitis in neonates. The Cochrane database of systematic reviews. 2015;3:Cd004205.

[104] Akdag A, Dilmen U, Haque K, Dilli D, Erdeve O, Goekmen T. Role of pentoxifylline and/or IgM-enriched intravenous immunoglobulin in the management of neonatal sepsis. American journal of perinatology. 2014;31:905-12.

[105] Travadi J, Patole S, Charles A, Dvorak B, Doherty D, Simmer K. Pentoxifylline reduces the incidence and severity of necrotizing enterocolitis in a neonatal rat model. Pediatric research. 2006;60:185-9.

[106] Patole S. ACTRN12606000257561. 2006.

[107] Biesterveld BE, Koehler SM, Heinzerling NP, Rentea RM, Fredrich K, Welak SR, et al. Intestinal alkaline phosphatase to treat necrotizing enterocolitis. Journal of Surgical Research. 2015;196:235-40.

[108] Eaton S, Zani A, Pierro A, De CP. Stem cells as a potential therapy for necrotizing enterocolitis. ExpertOpinBiolTher. 2013;13:1683-9.

[109] Zani A, Cananzi M, Fascetti-Leon F, Lauriti G, Smith VV, Bollini S, et al. Amniotic fluid stem cells improve survival and enhance repair of damaged intestine in necrotising enterocolitis via a COX-2 dependent mechanism. Gut. 2014;63:300-9. 
[110] Tayman C, Uckan D, Kilic E, Ulus AT, Tonbul A, Murat HI, et al. Mesenchymal stem cell therapy in necrotizing enterocolitis: a rat study. Pediatr Res. 2011;70:489-94.

[111] Yang JX, Watkins D, Chen CL, Bhushan B, Zhou Y, Besner GE. Heparin-Binding Epidermal Growth Factor-Like Growth Factor and Mesenchymal Stem Cells Act Synergistically to Prevent Experimental Necrotizing Enterocolitis. Journal Of The American College Of Surgeons. 2012;215:534-45.

[112] Wei J, Zhou Y, Besner GE. Heparin-binding EGF-like growth factor and enteric neural stem cell transplantation in the prevention of experimental necrotizing enterocolitis in mice. Pediatric Research. 2015;78:29-37.

[113] Ostergaard MV, Bering SB, Jensen ML, Thymann T, Purup S, Diness M, et al. Modulation of Intestinal Inflammation by Minimal Enteral Nutrition With Amniotic Fluid in Preterm Pigs. Journal of Parenteral and Enteral Nutrition. 2013.

[114] Siggers J, Ostergaard MV, Siggers RH, Skovgaard K, Molbak L, Thymann T, et al. Postnatal amniotic fluid intake reduces gut inflammatory responses and necrotizing enterocolitis in preterm neonates. AmJ Physiol GastrointestLiver Physiol. 2013;304:G864-G75.

[115] Good M, Siggers RH, Sodhi CP, Afrazi A, Alkhudari F, Egan CE, et al. Amniotic fluid inhibits Toll-like receptor 4 signaling in the fetal and neonatal intestinal epithelium. ProcNat|AcadSciUSA. 2012;109:11330-5.

[116] Jain SK, Baggerman EW, MohanKumar K, Namachivayam K, Jagadeeswaran R, Reyes VE, et al. Amniotic fluid-borne hepatocyte growth factor protects rat pups against experimental necrotizing enterocolitis. American Journal of Physiology-Gastrointestinal and Liver Physiology. 2014;306:G361-G9. 